\title{
EVALUATION OF EFFECTIVENESS OF LIGNOSULFONATE APPLICATION FOR ORGANIC COAL-WATER FUEL RHEOLOGICAL PROPERTIES IMPROVEMENT
}

\author{
Vitaliy Osipov ${ }^{1,}$, Kirill Larionov ${ }^{1}$, Alexander Matveev ${ }^{1}$, and Alexander Gromov ${ }^{1,2}$ \\ ${ }^{1}$ Tomsk polytechnic university, DNTPP, 634050 Tomsk, Russia \\ ${ }^{2}$ Nürnberg University of Technology Georg-Simon-Ohm
}

\begin{abstract}
The effect of lignosulfonate on viscosity of organic coal-waterfuel (OCWF) was investigated. Brown coal from "Borodinskoe" deposit, waste oil Motul 8100 X-Clean 5W-30-C3, distilled water and powdered lignosulfonate was used as raw materials for slurry preparation. OCWF viscosity were measured using a rotational viscometer BROOKFIELD DV-II + Pro EXTRA. Optimum lignosulfonate concentration was obtained $(1.3-1.4 \%)$.
\end{abstract}

\section{Introduction}

Various technologies of solid fuel combustion are currently actively developing [1]. One of the promising technologies is preparation of composite fuels using coal. Preparation and combustion of such composite as coal-water fuel (CWF) allows to decrease the harm caused to the environment compared to conventional coal combustion in a flow [2].

Despite the environmental advantages of CWF, this technology did not receive widespread introduction at energy facilities. Primarily, this is due to the fact that the concerned type of fuel has a number of not completely solved problems associated with low calorific value and high viscosity characteristics.

The problem of low calorific value of CWF may be solved by adding to its composition organic liquid fuels, which have higher energy characteristics compared to coal. This kind of fuel is called organic coal-water fuel (OCWF). The most successful kind of liquid fuel is waste oil, because it solves two problems at the same time: improves properties of composite fuel and provides a way for recycling waste oil, which would improve the environmental aspects of energy production [3].

In turn, the addition of oils in coal-water fuel sharply worsens viscosity characteristics, resulting in decreased reliability of the fuel and transport systems [2]

\footnotetext{
*Corresponding author: vitosipov93@mail.ru
} 
To solve this problem, the use of various surface-active agents (SAA) that can improve rheological properties of OCWF is proposed. In this paper, powdered lignosulfonate LST was used as a surfactant.

\section{Experimental setup}

Experimental studies of OCWF rheological properties using a powdered lignosulfonate LST were conducted using a rotational viscometer BROOKFIELD DV-II + Pro EXTRA at different spindle speeds and ambient temperature of $25^{\circ} \mathrm{C}$.

2B brand brown coal from "Borodinskoe" deposit was used as initial solid fuel sample. After initial processing in a ball-mill pulverizer, it was sieved through a sieve with a mesh size of 80 microns. Further, received material was stirred in a galvanized drum with a volume of 0.5 liter with spherical grinding bodies with a diameter of $5 \mathrm{~mm}$ and a weight ratio of 1:1. In addition to pulverized coal, distilled water, waste oil Motul 8100 X-Clean $5 \mathrm{~W}-30-\mathrm{C} 3$ and powdered lignosulfonate LST with different concentrations presented in Table 1 were added in the drum.

After mixing of the materials, the drum with OCWF was placed in a Fritsch Pulverisette 7 Micro Mill planetary mill, in which wet milling was carried out for 5 minutes at a speed of $500 \mathrm{r} / \mathrm{min}$.

Upon reaching the predetermined time of grinding, the resulting suspension was poured into a measuring cylinder with a volume of 0.25 liter and dynamic viscosity was measured.

Table 1. Mass concentrations of studied OCWF samples.

\begin{tabular}{|c|c|c|c|c|}
\hline \multirow{2}{*}{$\begin{array}{c}\text { Sample } \\
\text { number }\end{array}$} & \multicolumn{4}{|c|}{ Mass concentration, \% } \\
\cline { 2 - 5 } & Coal & Oil & Water & Lignosulfonate \\
\hline 1 & 50 & - & 50 & - \\
\hline 2 & 44 & 4 & 52 & - \\
\hline 3 & 46 & 2 & 52 & - \\
\hline 4 & 45 & 5 & 50 & - \\
\hline 5 & 45 & 5 & 49 & 1 \\
\hline 6 & 45 & 5 & 48.5 & 1.5 \\
\hline 7 & 45 & 5 & 48 & 2 \\
\hline 8 & 45 & 10 & 44 & 1 \\
\hline 9 & 45 & 10 & 43.5 & 1.5 \\
\hline 10 & 45 & 10 & 43 & 2 \\
\hline
\end{tabular}

\section{Results}

The obtained results of prepared OCWF samples dynamic viscosity dependence from the spindle rotation speed and concentration of lignosulfonate are shown in figures 1 and 2. 


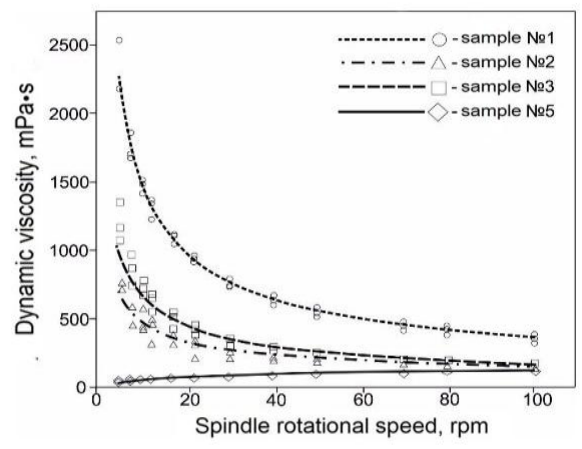

Fig. 1. The dependence of dynamic viscosity from spindle rotation speed.

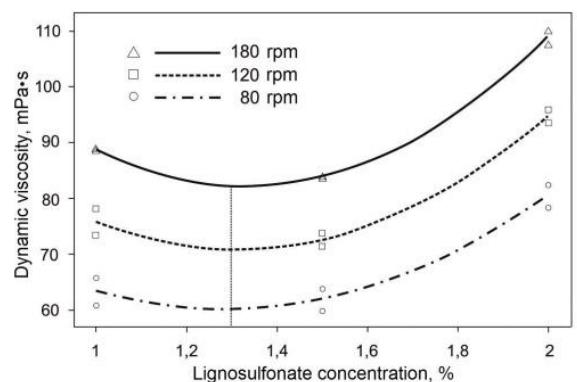

a

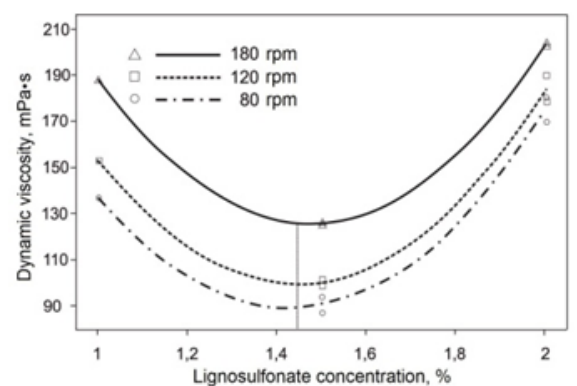

$\mathrm{b}$

Fig. 2. The dependence of dynamic viscosity coefficient from lignosulfonate concentration (a samples \#5, 6, 7; b - samples \#8, 9, 10).

Conducted experimental studies showed that a small amount of added oil can lead to a strong mixture viscosity increase. During the experiment, concentration of coal and oil $44 \%$ and $4 \%$, respectively, with no added surfactant was achieved (sample No. 2). A further increase in the solid part (sample No. 4) led to a sharp increase in viscosity, making the fuel non-flowing.

Figure 1 shows that viscosity of the sample dramatically decreases with an increase of spindle speed, indicating pseudoplastic nature of the slurry.

The results presented in figure 2 represent the effect of lignosulfonate, which can significantly reduce fuel viscosity at low shear rates, thus changing the nature of the dependence - dynamic viscosity increases with an increase of spindle rotation speed, while its range of variation becomes narrower. Thus, the injection of this additive allows further increasing of the combustible portion of the fuel.

Figure 2 illustrates that the addition of lignosulfonate lowers OCWF viscosity with increasing its concentration up to only a certain limit. Further increase in the amount of lignosulfonate leads, on the contrary, to an increase in fuel viscosity.

Figure 2 shows that the optimum value of the lignosulfonate amount in OCWF is about $1.3-1.4 \%$ at concentration of $5 \%$ oil and $45 \%$ coal and $1.4-1.5 \%$ at concentration of $10 \%$ oil and $45 \%$ coal. 


\section{Conclusion}

Experimental study of OCWF rheological properties showed that the presence of waste oil in the composite fuel greatly increases viscosity. Solution to this problem is achieved by adding a lignosulfonate surfactant, thereby reducing viscosity of the slurry and increasing content of the combustible portion in OCWF. Despite this, an excessive increase of lignosulfonate concentration in the composite fuel gives a negative effect.

Thus, it was determined that all samples of OCWF have optimum lignosulfonate concentration $1.3-1.5 \%$.

\section{Acknowledgments}

The research was realized with financial support of Minobrnauki of Russia in framework of FTP "Research and development in prior direction of scientific-technological complex of Russia in 2014-2020 years", unique R\&D identifier RFMEFI58114X0001.

\section{References}

1. K.V. Slyusarskiy, M.K. Bejsekov, J.V. Marysheva, Y.Ja. Rakov MATEC Web Conf. 37 (2015)

2. Osintsev K.V. Energy and resource saving in power engineering and the social sphere 1, $242(2013)$

3. D.V. Gvozdyakov, V.E. Gubin, Chem. and Petrol. Eng. 6 (2015)

4. D.O. Glushkov, D.P. Shabardin, P.A. Strizhak, K.Y. Vershinina, Fuel Process. Technol. 143 (2015)

5. G. Atesok, F. Boylu, A.A. Sirkeci, H. Dincer, Fuel 81 (2002)

6. G.S. Khodakov, E.G. Gorlov, G.S. Golovin, Solid Fuel Chem. 40 (2006)

7. R. Chen, M. Wilson, Y.K. Leong, P. Bryant, H. Yang, D.K. Zhang, Fuel 90 (2011) 